\title{
ATTITUDES TOWARDS MARRIAGE AND THE DESIRED NUMBER OF CHILDREN IN NORTH MACEDONIA
}

DOI: https://doi.org/10.18509/GBP210203lj

UDC: 316.362.4:303.6(497.7)

\author{
Marija Ljakoska \\ Ss. Cyril and Methodius University in Skopje, Faculty of Natural Sciences and Mathematics, \\ Institute of Geography, North Macedonia
}

\begin{abstract}
This time of social change that we all live in, goes along with the population natural change as well. The vital statistics data regularly published by the State Statistical Office are really good pointers to the changes that have taken place in the marital and reproductive behavior of the population in the country. They are also the basis for calculating the main population indicators and indexes. Unfortunately, they don't provide data related to the attitudes towards marriage and the desired number of children, family planning, the reasons that have caused these changes nor analysis of the changes that occurred as a result of the few population policy measures implemented so far.

The study in the paper is based on the analyzes of the results from the conducted anonymous survey "Attitudes towards marriage and the desired number of children", with more than 3,000 respondents of reproductive age in North Macedonia, i.e. women aged 15-49, and men aged 15-64.

The results from the survey showed significant differences between the answers of women and men, and they also differed depending on the age of the respondents.

Therefore, the study recommends several effective institutional strategies and population policy measures in order to overcome the challenges related to population natural change and to reduce the contemporary regional differences in population development.
\end{abstract}

Keywords: attitudes, marriage, children, survey, North Macedonia

\section{INTRODUCTION}

Attitudes towards marriage and divorce are of interest to demographers, geographers, and the general public as they greatly influence the family formation, family composition, and fertility [7]. Marriage (partnership) and family (parenthood) are very important life goals that are at the level of preferred values and life practices [2]. Namely, analyzing marital behavior is approached in terms of its importance for fertility, bearing in mind that marriage is a framework in which population reproduction most often occurs [6].

The changes in marital behavior do not occur in isolation. They are closely related to the socio-economic changes and are in line with the characteristics of modern society, such as the process of urbanization, the long-term educational process, the increased opportunities in the consumer society, the emancipation of women, the aspiration for personal success, individualization, etc. The main reasons that conditioned these changes in the number of marriages are in the sphere of socio-economic conditions, pronounced differences in the population gender and age structure at the regional and local level, migration, social and political changes, state stability, transition process, and more [8].

The administrative data sources are usually limited because they only consist data that citizens are required to provide to state institutions. Therefore, it was necessary for these 
data to be upgraded with empirical research using survey technique, with a questionnaire as an instrument, as could be analyzed the population opinions and attitudes. The structure of every attitude can be explained and understood with three aspects: the one that involves a person's feelings or emotions, the second aspect is behavioral and includes the way people act or behave, and the third one involves person's belief or knowledge [10], [14]. The opinions and attitudes are facts and data which processed and analyzed can represent important scientific conclusions. Therefore, it was conducted this empirical research which resulted in an extensive fund of information.

\section{METHODOLOGY AND LITERATURE REVIEW}

Demographic data, i.e. population data have multiple meanings. They are used to analyze and display certain conditions, monitor changes and regularities of development. In that sense, they have a scientific meaning, but they are also applicable. Without this data, serious population research cannot be realized, but they are also a basis on which complementary methods can be applied.

Choosing an adequate method in the research process in any scientific discipline is a very important and complex task. Usually, for a more detailed and complete study of the population, for a serious perception of the situation and clarification of everything that happens within a particular population are used empirical researches. In order to directly, objectively, and practically obtain information and data on what is the subject of research, and which further will contribute to a more detailed acquaintance with the studied phenomena and processes are used these types of researches. It is a special chain link in the complex process of analyzing the population, which often appears as a starting point or a complement to the theoretical research of the population. In fact, through their organization and implementation, in-depth research of the population is carried out. They can be defined in different ways, but, most often, they are seen as well-organized activities through which information and population data are collected, which are further the basis for additional and thorough researches.

The phenomenon we want to know or to research is called the population, and the part we study is called a sample. For the sample to be representative, it should poses features similar to the basic set or it should be the basic set shown on a smaller scale. The sampling method is based on the examination of a relatively small number of randomly selected persons, in order to obtain information on the observed mark of the entire population [13]. Due to the fact that the purpose of the empirical research is to directly, objectively, and practically collect data and information, a survey was conducted, online and in the field. The online survey was conducted using the Google Docs forms tool. Using this tool, the questionnaires were answered online and the results were available at any time, even before the survey was completed. The random sampling approach was used for the survey, and the survey, which lasted several months, ended in February 2019.

Although the field survey is a relatively longer and more expensive method of research, it is still one of the most valuable and accurate ways to gain insight into the surveyed population. The field survey for the needs of this research was conducted by distributing questionnaires to randomly selected respondents, but also to students from 4 high schools in 4 urban municipalities in different parts of the country (Kisela Voda, Chair, Kumanovo, and Kichevo), as well as students from the Ss. Cyril and Methodius University in Skopje, Faculty of Natural Sciences and Mathematics.

From the total number of respondents included in the survey, due to incomplete questionnaires and due to inappropriate age (age outside the fertility period), their number 
was reduced to 3,170 responses. They belong to different age groups of the fertile period in a person's life, i.e. between 15 and 49 years of age for women and 15 to 64 for men. The survey was conducted on the basis of a previously prepared questionnaire consisting of 26 questions, of which 18 were closed and 8 were the open type of questions. Two of the questions were Likert scale ${ }^{3}$ type of questions, with an agreement scale of five-points used to measure respondents' attitude towards marriage and having a child. The answer to 25 questions was mandatory, while in one of the questions the respondents had the option to choose whether to answer or not. The questions were divided into three sections:

- The first section referred to the attitudes of the respondents towards marriage and marital behavior (11 questions);

- The second section was composed of questions about the attitudes towards the reproductive behavior and family planning (8 questions);

- While the third section was composed of personal questions for the respondent such as gender, age, ethnicity, education, activity, and place of residence (7 questions).

The respondents have different levels of education and different marital status, in order to get a more realistic picture of the opinions and attitudes of the population when it comes to marriage and fertility. Anyhow, the main target group was the opinion and attitude regarding this particular issue of the population with higher educational level, which is people with a college, master or Ph.D. degree, due to the fact that this kind of data is not available elsewhere.

In order to analyze the population, it is more than necessary to make statistical data processing. The analyzes were conducted using Microsoft office excel 2013, to create tables and figures based on the survey data, and the goal was to obtain an overview of the given problem.Fertility and marriage in North Macedonia have been the subject of research in numerous scientific papers in the field of geography. But, this paper and the one about the reproductive behavior of the Roma female population by Apostolovska Toshevski et al. [1], in 2018, are the first attempts of making scientific geography papers related to attitudes toward marital and reproductive behavior of the population where the main data sources are those obtained from such field empirical researches.

\section{RESULTS AND DISCUSSION}

The vital statistics data regularly published by the State Statistical Office are really good indicators of the changes that have taken place within the marital and reproductive behavior of the population. Namely, those data can help in following the number of marriages and divorces, as well as the number of newborn children over the years. However, these data do not provide information related to family planning or analysis of the effect of the population policy measures. We obtained that information from the respondents' answers.

\section{Respondents' attitudes towards marriage and marital behavior}

Attitudes towards marriage, among other things, are closely related to the marital status of the respondents, their age, their level of education, and the conditions in which they live. In this survey, most of the respondents answered that they are married, followed by the number of those who answered that they are not married, i.e. they are single or unmarried.

\footnotetext{
${ }^{3}$ https://www.questionpro.com/article/likert-scale-survey-questions.html
} 


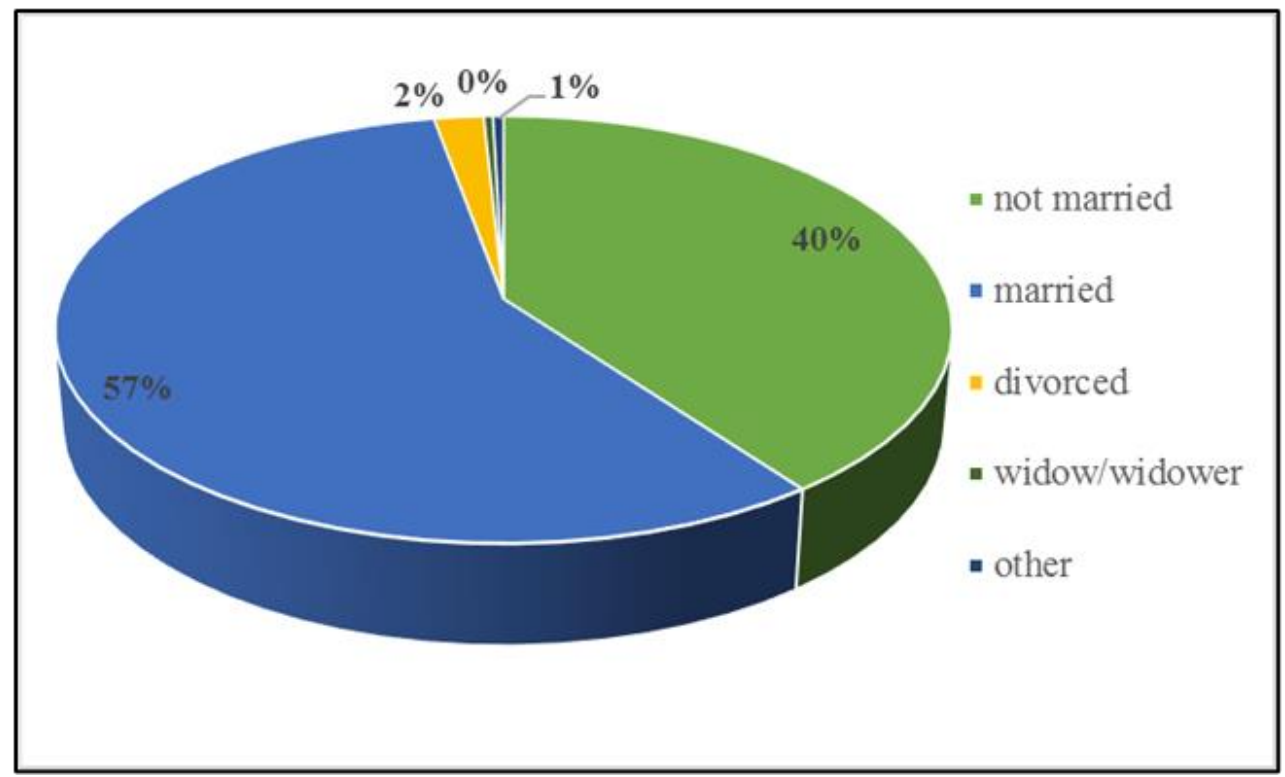

Figure 1. Respondents' marital status

From the answers analysis done by respondent's gender, we could see that most of the surveyed women had the status of married (69.4\%), while men were mostly single $(74.8 \%)$.

In addition to the gender analyses, the respondents were also divided according to their age, i.e. young people up to 29 years of age, and persons of 30 years and older. Of the total number of young people $62.7 \%$ were unmarried, while in the group of older respondents', this percentage was only $12.9 \%$. Even $82.3 \%$ of the respondents older than 30 answered that they were married.

When asked about the age of getting married for the first time, there were numerous answers ranging from the age of 16 to 45 , but the average age at which the respondents got married is 25.8 years. For women, this age is slightly below the average, i.e. 25.4 years, while for men the average age was close to 28 years. People who were married and belong to the group of young population, on average, got married at the age of 23.1, while people over 30, on average, got married at the age of 27 . A wide range of answers were given to the question regarding the length of the marriage. There could be found answers that the marriage lasted from a few months to a maximum of 32 years (on average 5.5 years out of the total number of answers given as numbers), but most respondents answered that their first marriage still lasts.

Even $95.5 \%$ of the respondents who were married, said that the marital union they were in at the moment, was their first. Re-married for a second time were $2.4 \%$ respondents, while only $0.1 \%$ were in a marriage union which at the time of conducting the survey was their third. At the time of the survey, married for the first time were $95.8 \%$ women, and $92.7 \%$ of men. Only $2.3 \%$ of the surveyed women and $3.9 \%$ of the surveyed men were in a second marriage. One woman and one man answered that the marital union in which they are currently in, is their third. Even $97.3 \%$ of young people were married for the first time, while the percentage of people over 30 who were in their first marital union was $94.6 \%$. 


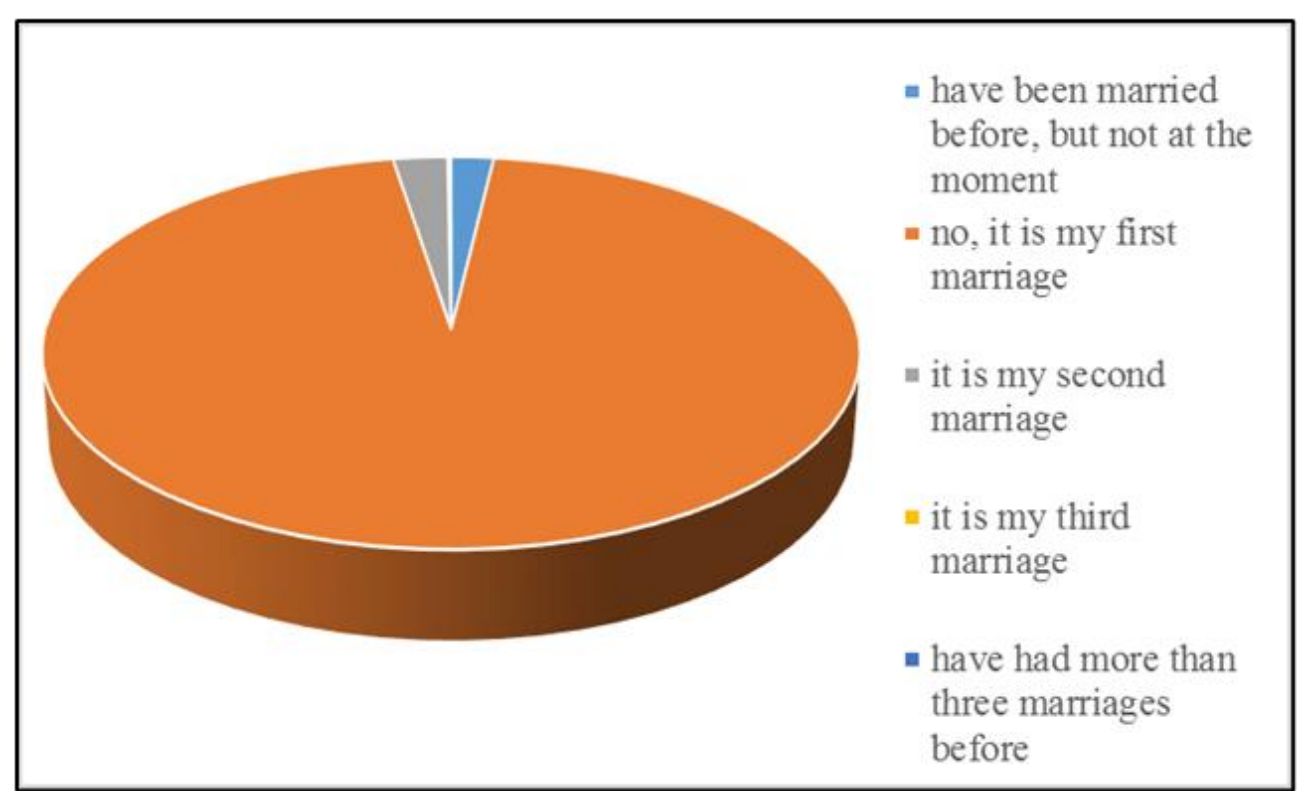

Figure 2. Answers to the question: Have you been married before or is this your first marriage?

The period of life in which most men and women enter into marriage is determined by the characteristics of the global social system, family, and marriage [12], [4]. Because the age of marriage is one of the most important determinants of reproductive behavior, the best years for marriage are those in which there are maximum biological prerequisites to achieve the greatest reproduction. However, with changing lifestyles in today's, modern societies, the process of individuation and adopted system of values, the attitudes of individuals to marriage as an institution, and the "perfect time" for getting married have significantly changed [4].

The answers about the ideal age at which a man and a woman should get married are quite different, but on average, respondents believe that a woman should get married before the age of 26, while the ideal age for a man to get married is considered as the age of 28 . Women's attitudes are quite different from those of men, especially about the age of marriage for men. Thus, women think that it is best to get married at the age of 25.9 years for a woman and 28.3 years for a man, while men think that a woman should get married at the age of 25.3 years, while a man at the age of 27.2 years. The answers of respondents no older than 29 differ from those older than 30. Namely, those who belong to the category of the young population believe that a woman should get married at the age of 25.3 and a man should get married at the age of 27.4, while others think that they should get married at a slightly older age, i.e. 26.3 years for women and 28.9 years for men.

When asked if they plan to get married, most of the respondents who were not married answered that they plan to get married (32.6\%), $4.7 \%$ of the respondents answered that they will not get married, while $8.5 \%$ answered that they haven't thought about it yet.

Most surveyed women were married (63.6\%), a quarter said they want to get married, while only $4.4 \%$ did not want to get married. The others replied that they had not yet thought about it. Nearly a quarter of surveyed men were married, and more than half wanted to get married at some point. Approximately one-half of young people under the age of 29 who were unmarried said they would like to do it in the future. 


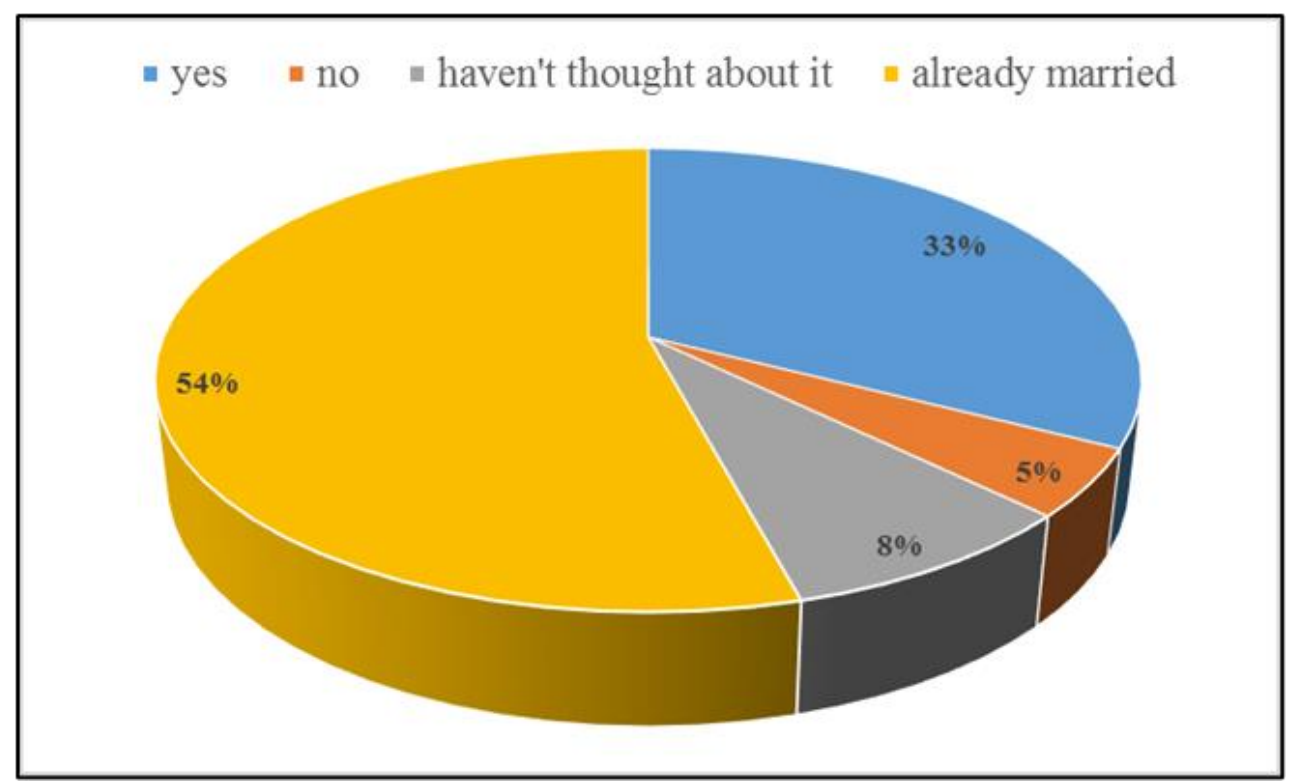

Figure 3. Answers to the question: If you are not married, are you planning to get married?

Most of the respondents, (54\%) answered that they would decide to live with their partner before marriage, $13 \%$ were already living, and $14.4 \%$ would probably decide not to do it. More than half of the surveyed women and men answered that they would live, or lived with their partner before marriage, and over $50 \%$ of the respondents of both age categories gave the same answer.

The share of surveyed females who already lived in cohabitation with their partner before marriage was higher than the share of men, that is, $14.5 \%$ versus $7.9 \%$. Just over $12 \%$ of respondents under the age of 29 answered that they already live with their partners, compared to $14 \%$ of people over the age of 30 .

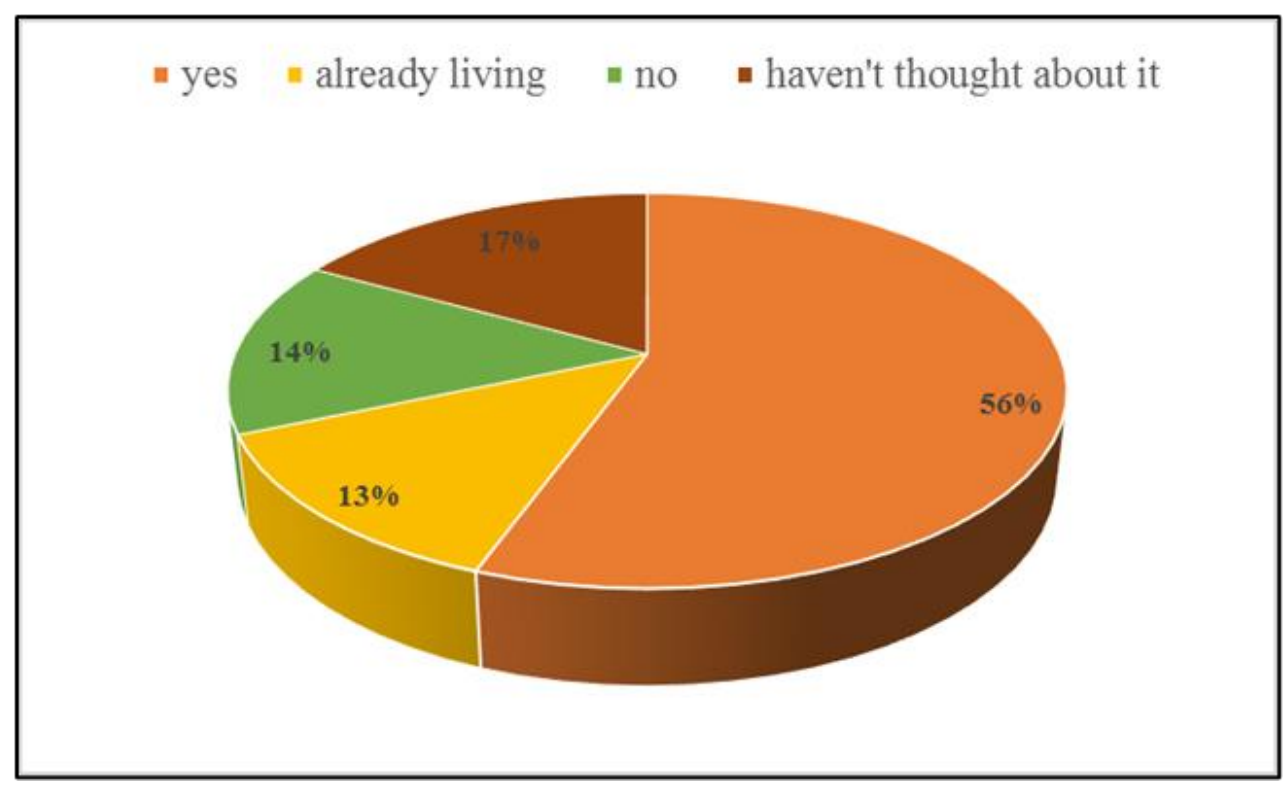

Figure 4. Answers to the question: Would you decide to live (or already live) with your partner before getting married?

Such changes are due to changes in society, new views and perceptions of lifestyle, the higher level of education of women, the desire for personal success, and women's 
involvement in the labor market that creates greater independence. In particular, if in the past, women got married because they did not have their own income or place of residence and were mostly dependent on their husbands, this is less and less the case in recent years. Questions about respondents' attitudes on the decision to marry a person who has been previously married depend on whether or not the person has children from that marriage. According to their answers, it can be noticed that a much larger number of respondents would marry a person who was previously married, but would not decide to take such a step if the person has children from that marriage. Thus, in the first case "yes" was the answer of $26.4 \%$ of respondents, while in the second case, the percentage dropped to $19.1 \%$. "No" was the answer of $17.9 \%$ of the respondents for the first case scenario, and even $28.1 \%$ for the second case. Such values show that our society is beginning to accept the demographic trends that are present in developed European countries and the United States, but it seems that a longer period of time should pass before these behaviors are fully accepted.

About a quarter of surveyed women would marry men that have been married before, even if they have children. Men, unlike women, answered that they would marry a woman who had been married before (31\%), but a much smaller share answered that they would decide to enter such a union if the woman had children from a previous marriage (19.8\%). The different attitudes of men and women on this issue are really highlighted.

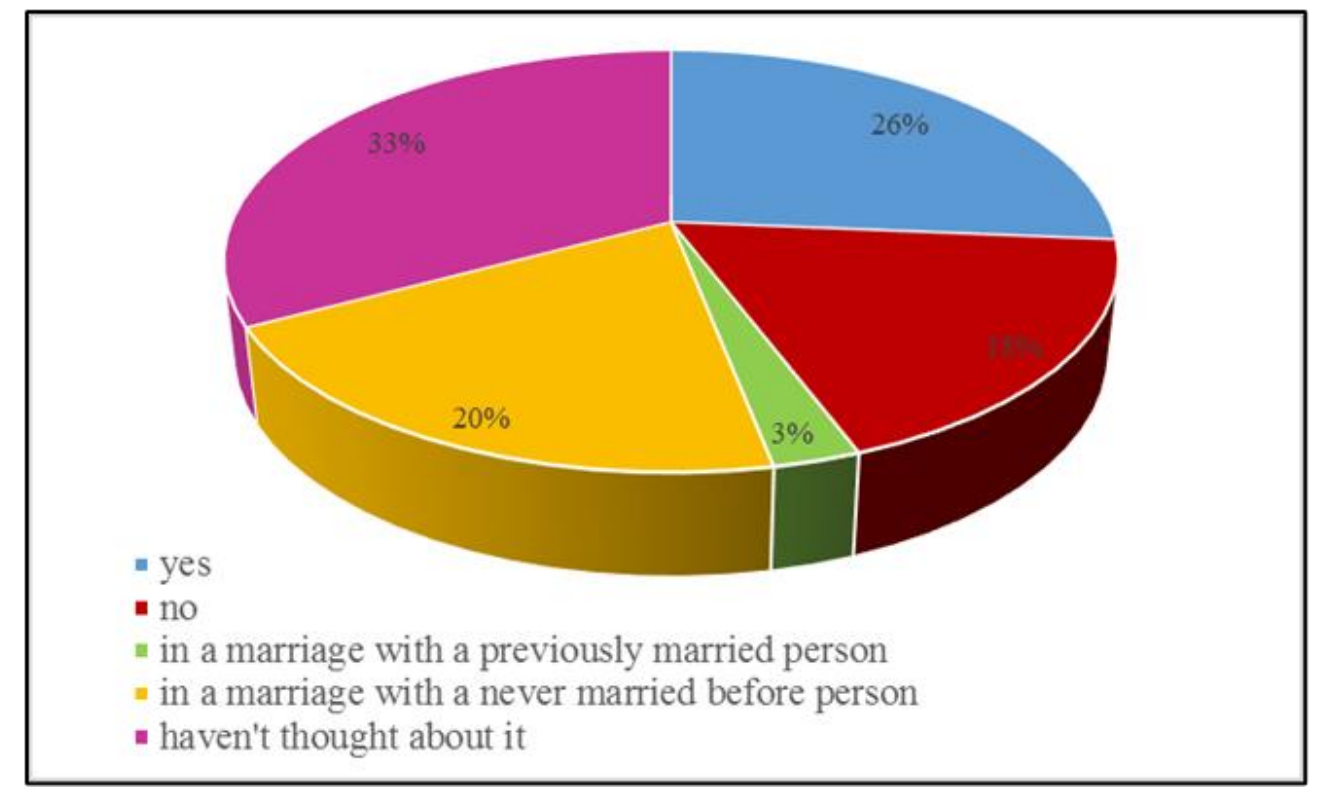

Figure 5. Answers to the question: If you were not previously married, would you decide to marry someone who was previously married (divorced; widow/widower)?

Almost one-quarter of young people answered that they would not marry a person who was previously married, and more than a third would not do so with a partner who was previously married and has children from that marriage. Just over $30 \%$ of people over the age of 30 answered that they would marry a person who has been married previously, and only a quarter of these respondents would marry a partner who has children.

Different factors have different influences on the decision if, whether, or when would people get married. Therefore, it was used a Linkert scale type of question, where several factors were listed and scaled answers were offered from 1 to 5, i.e. from completely unimportant to very important, (1 - completely unimportant; 2 - mostly unimportant; 3 - 
neither important nor unimportant; 4 - partially important; 5 - very important). The average rating for each of these factors is represented in table 1.

Table 1. Average rating of the importance of each of the listed factors for the decision to get married

\begin{tabular}{|c|c|c|c|c|c|}
\hline \multirow[b]{2}{*}{ Question } & \multicolumn{5}{|c|}{ Average rating } \\
\hline & Total & Women & Men & $\begin{array}{l}29 \text { years and } \\
\text { younger }\end{array}$ & $\begin{array}{l}30 \text { years } \\
\text { and older }\end{array}$ \\
\hline Suitable partner & 4.7 & 4.7 & 4.6 & 4.7 & 4.7 \\
\hline Unplanned pregnancy & 3.0 & 3.0 & 3.1 & 3.2 & 2.9 \\
\hline Fear of being/living alone & 1.9 & 1.9 & 2.1 & 1.9 & 1.9 \\
\hline My personal economic status & 2.5 & 2.3 & 3.0 & 2.6 & 2.3 \\
\hline $\begin{array}{l}\text { The economic status of the potential } \\
\text { partner }\end{array}$ & 2.4 & 2.4 & 2.6 & 2.5 & 2.3 \\
\hline The financial situation & 2.8 & 2.6 & 3.2 & 2.9 & 2.6 \\
\hline Work engagement (career building) & 2.8 & 2.7 & 3.2 & 3.0 & 2.6 \\
\hline Resolved/unresolved housing issue & 3.0 & 2.9 & 3.3 & 3.0 & 2.9 \\
\hline $\begin{array}{l}\text { Government measures (Buy a house, buy } \\
\text { an apartment; Buy a house for people } \\
\text { younger than } 35 \text { years) }\end{array}$ & 1.8 & 1.7 & 2.0 & 1.9 & 1.7 \\
\hline
\end{tabular}

Source: author's calculations using survey data.

According to respondents, undoubtedly, the most important factor for the decision of getting married or not is finding a suitable partner. Then comes the unplanned pregnancy as a factor and the housing issue. The least important to the respondents are the measures as part of the Governmental program with an average score of 1.8.

This fact is only a confirmation that young people decide to live in cohabitations and probably get married only when they want to have children, or the children are on the way [15], i.e., even in cases when the first child is conceived when the couple is unmarried, birth takes place within a marital union, because marriage is still being the most desirable, appropriate context for giving birth and raising a child [5].

Different factors are priorities for women and men. Women gave higher marks than men only for choosing a partner, while men give more importance to the economic status, finances, and housing. This indicates that in our country, despite all the social changes and changes in marital behavior, the traditional belief that the man is the one who should provide the home and the one that should take care of the family is still present. However, assessments of the importance of these factors among young people show that changes in attitudes and opinions do occur, as they give less importance to these factors compared to people aged 30 and over.

\section{Respondents' attitude towards reproductive behavior and family planning}

In a previously conducted survey about the family size, most respondents said two children was an ideal number. However, it seems that the ideal family size in most European countries is becoming smaller [16]. This was confirmed by the answers received from this survey as well.

The section about reproductive behavior and family planning begins with the question of how many children a family should have. Most of the respondents have no specific opinion, $37.3 \%$ answered that there is no ideal number, but it depends on several factors. For just over $40 \%$ of women, there is no ideal number, close to $29 \%$ answered that the family should have two children, and $27 \%$ answered that the ideal number of children is three. Men have more specific opinions, and even $35 \%$ answered that the family should have two children, while $31.7 \%$ answered that having three children is probably the best. 


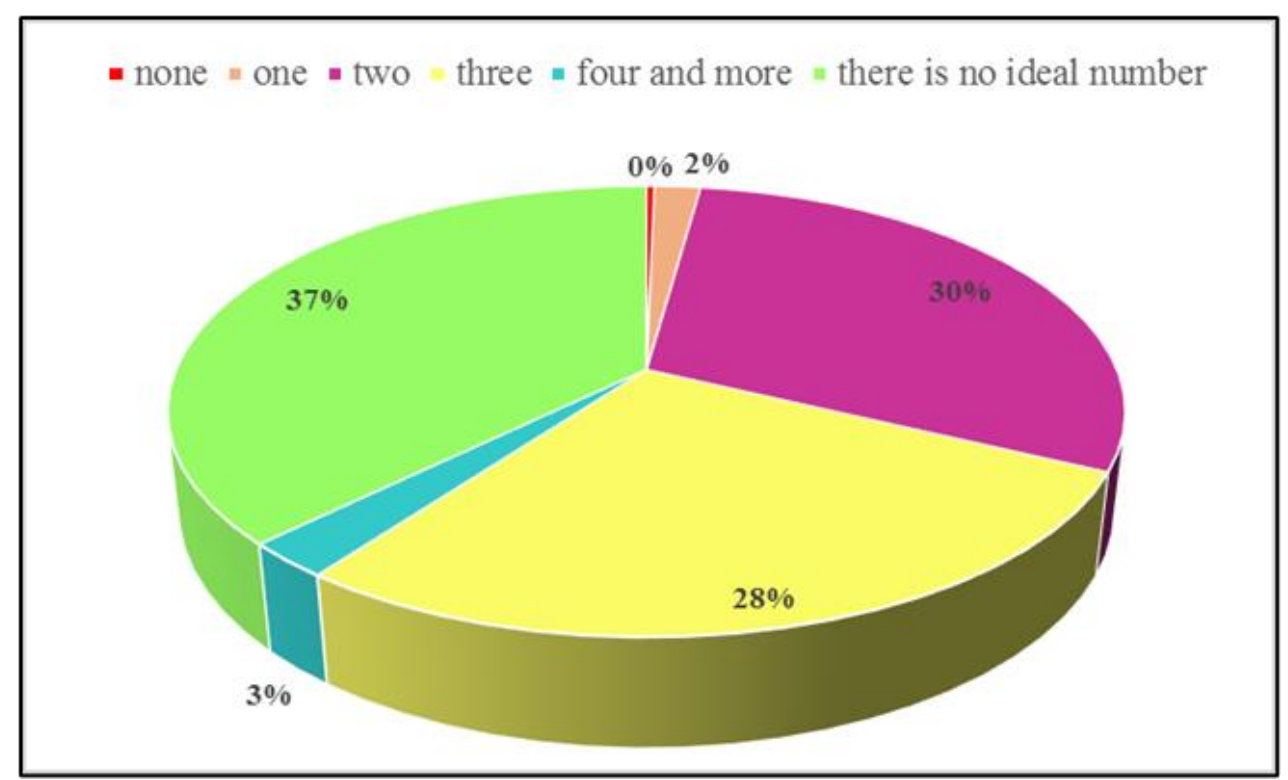

Figure 6. Answers to the question: In your opinion, how many children should a family have?

Nearly half of the respondents did not have children (45.6\%). Only one child had $28.3 \%$ of the respondents, while $21.9 \%$ had two children. The share of those having three children was $3.8 \%$, and $0.4 \%$ had four or more children. The average age at which respondents with child/children had or gave birth to their first child was 27 years (26.9 years for women; 28.6 years for men).

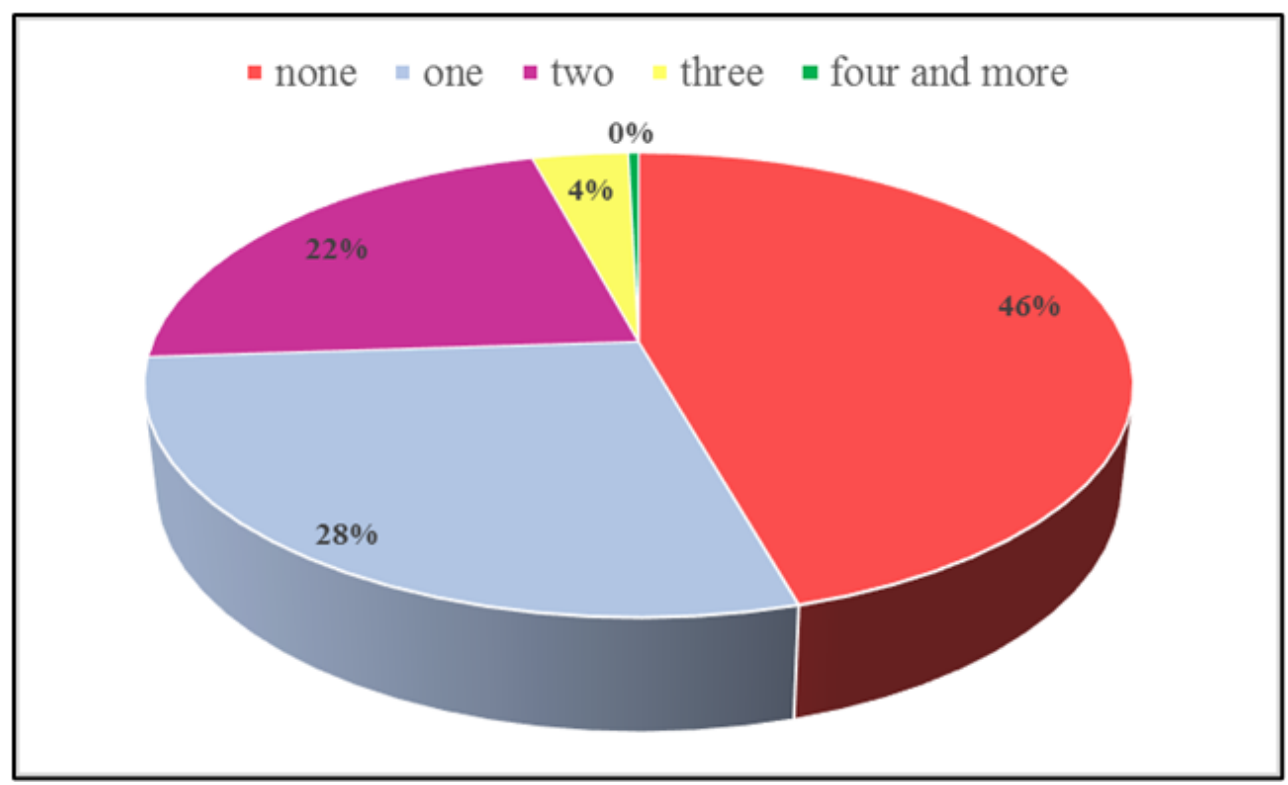

Figure 7. Answers to the question: How many children do you have?

In the opinion of all respondents, the ideal age for a woman to have her first child is 26.3 years, while for men, it is considered the age of 28.5 years. Women believe that the ideal age for a woman to have her first child is 26.4 , and for men, they point to the age of 28.8 years. On the opposite, men are considering a younger age, for both women (25.9 years) and men (27.7 years). People under the age of 29 think that the ideal age for a woman to give birth is 26 , and for man 28 , compared to people over the age of 30 who think that 
couples should have a child at a slightly older age, i.e. 26.6 years for the woman and 29.1 years for the man.

When asked if and how many children they still plan to have, $29 \%$ of the respondents answered that they want 2 children, $16.4 \%$ waned 3 children, $15 \%$ wanted only 1 child, and $2.6 \%$ wanted four or more children. With no exact opinion on the subject were 22.9 $\%$ of the respondents, while even $13.8 \%$ stated that they do not want to have a child at all. Most women (28.3\%), as well as most men (33.1\%) wanted two children. The same was the answer for $35 \%$ of people younger than 29 years, and $22.6 \%$ persons older than 30 . Only $5.6 \%$ of young people answered that they do not want to have a child.

Opinions on whether they would choose to give birth or have a child outside of a marital union are almost equally divided in three because $35.7 \%$ said they would not have a child out of wedlock, $32.3 \%$ would choose to have a child out of wedlock, while $32 \%$ said they had not thought about it. The opinions of the surveyed women on this issue are almost equally divided, while the majority of men, $43 \%$ answered that they would probably not make such a life decision. Nearly half of people under the age of 29 would not have a child outside marriage, while almost $40 \%$ of people aged 30 and over said they would choose to have a child even if unmarried.

This phenomenon of mothers deciding to give birth to a child outside marriage is increasing in the past years, but varies depending on the cultural differences, especially given the fact that in many societies, giving birth outside marriage is still considered a deviant behavior [3]. On the other hand, births outside marriage are one of the elements that bear the "signature" of the second demographic transition [11], and in the modern world, single motherhood is "normal" and no longer a shame.

Similar to the previous section, several factors were listed and considered as important in deciding whether and if an individual should have a child. The questions were offered with graded answers from 1 to 5, i.e. from completely unimportant to very important. The average grades were pointing that the respondents considered the health of the mother as well as the support of the partner as the most important factors in the decision to give birth to a child. No less important was considered the health of the father. All other factors are much less important for the respondents, while the Government measures are rated as least important, with the lowest average grades.

For women and people up to the age of 29 , the most important was the number of kindergartens and the support of the partner and parents for the decision to have a child. 
Table 2. Average assessment of the importance of each of the listed factors for the decision to have a child/another child

\begin{tabular}{llllll}
\hline \multirow{2}{*}{ Question } & \multicolumn{3}{l}{ Average rating } & & \\
\cline { 2 - 6 } & Total & Women & Men & $\begin{array}{c}\text { 29 years and } \\
\text { younger }\end{array}$ & $\begin{array}{l}30 \\
\text { and older }\end{array}$ \\
\hline The health of the mother & 4.4 & 4.4 & 4.4 & 4.5 & 4.4 \\
\hline The health of the father & 4.3 & 4.3 & 4.3 & 4.4 & 4.2 \\
\hline The economic status of the mother & 3.5 & 3.6 & 3.1 & 3.5 & 3.5 \\
\hline The economic status of the father & 3.6 & 3.6 & 3.5 & 3.7 & 3.5 \\
\hline Costs for children & 3.5 & 3.5 & 3.3 & 3.6 & 3,4 \\
\hline The financial situation & 3.8 & 3.9 & 3.7 & 3.9 & 3.7 \\
\hline $\begin{array}{l}\text { The possibility of extending paid } \\
\text { maternity leave }\end{array}$ & 2.9 & 2.9 & 2.8 & 2.9 & 2.9 \\
\hline $\begin{array}{l}\text { The possibility of using maternity } \\
\text { leave for the father }\end{array}$ & 2.6 & 2.6 & 2.6 & 2.7 & 2.6 \\
\hline $\begin{array}{l}\text { Flexible working hours for parents of } \\
\text { young children }\end{array}$ & 3,4 & 3,4 & 3.2 & 3.4 & 3.4 \\
\hline Work engagement (career building) & 3.0 & 3.0 & 3.1 & 3.1 & 2.9 \\
\hline $\begin{array}{l}\text { The number of kindergartens and their } \\
\text { capacity }\end{array}$ & 3.0 & 3.0 & 2.7 & 2.9 & 3.1 \\
\hline Partner support & 4.4 & 4.5 & 4.3 & 4.5 & 4.4 \\
\hline Support and help from the parents & 3.7 & 3.7 & 3.6 & 3.8 & 3.6 \\
\hline $\begin{array}{l}\text { Government measures (have a third } \\
\text { child; allowance for a fourth child) }\end{array}$ & 2.1 & 2.1 & 2.2 & 2.2 & 2.1 \\
\hline $\begin{array}{l}\text { The political situation in the country } \\
\text { Source: }\end{array}$ & 2.4 & 2.3 & 2.7 & 2.3 & 2.4 \\
\hline
\end{tabular}

Source: author's calculations using survey data

\section{Demographic characteristics of the respondents}

Most of the respondents in the survey were women, (77.6\%), while the share of men was quite lower $(22.4 \%)$. The respondents were of different ages, but the most common age groups were from 25 to 29 years and 30 to 34 .

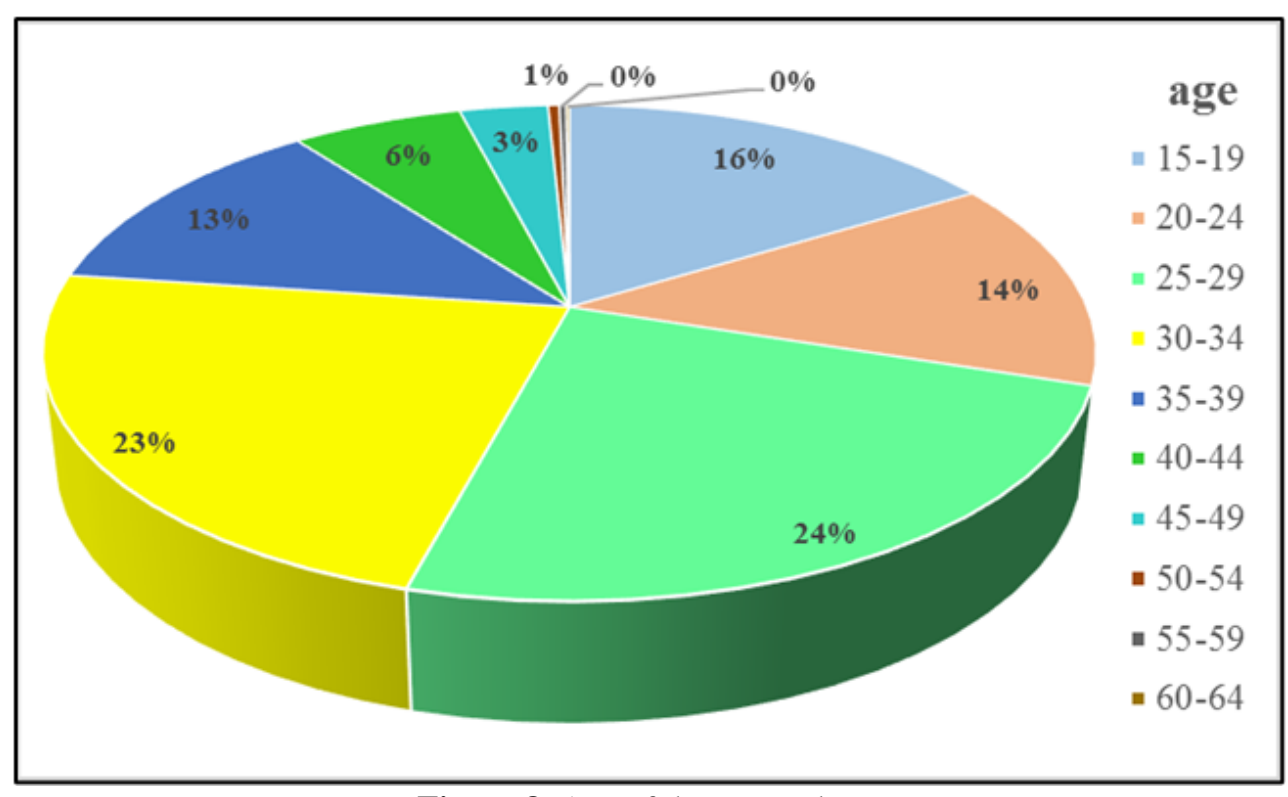

Figure 8. Age of the respondents 
Most of the women, i.e. just over half, were aged 25 to 34, while at that same age were one-third of the men that took part in this survey. About $70 \%$ of the respondents under the age of 29 were women, and the share of women older than 30 years was even $85.3 \%$. Most of the respondents, i.e. over $90 \%$ declared themselves as Macedonians.

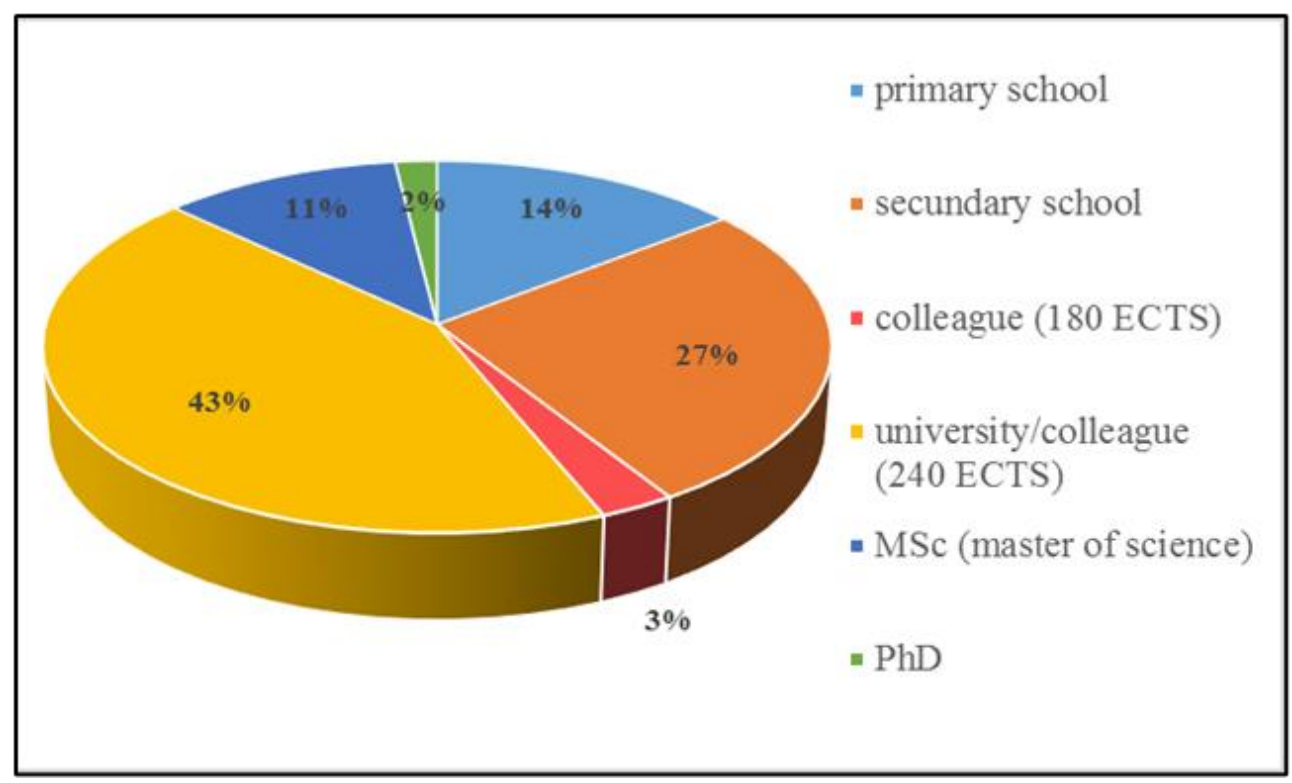

Figure 9. Respondents' education

Most of the respondents have had a colleague or university degree, followed by the number of those with high school diplomas, and then the respondents with completed only primary education. However, these data should be taken with caution, as a large number of respondents who took part in the survey, given their age, were still in the educational process. Almost half of the surveyed women had obtained higher education, and with that same level of education were $32 \%$ of the men respondents.

The results indicate that the respondents, especially women, have a higher level of education that is due to changes in the educational structure of the population, especially the involvement of women in the educational process. A higher level of education is a kind of guarantee for a more stable job, which means a more stable future, especially for women. In the past women were not able to support themselves, but this is not the case today. Therefore, it would be much easier for women with higher education who are likely to be employed and have a solid income to decide to end their marriage and even to have a child without a partner.

More than half of the persons were employed. Nearly $60 \%$ of the women in this survey were employed, while $13.8 \%$ were students. Among men, $40 \%$ of the respondents were employed, and $44.2 \%$ had the status of a pupil or student.

The last question, which was the only non-mandatory question, was answered by a total of 3,106 respondents. Of the total number of answers, $14.3 \%$ choose "I do not want to answer", and only $2 \%$ of the respondents did not answer at all. Most of the women who answered what their incomes are, earned between 20,000 and 30,000 MKD (which is between 330 and 500 EUR) per month. The share of those who earned between 12,000 and 20,000 MKD (200 and 330 EUR) or have no income is approximately the same. Most men had no income, i.e. 34.4\%, while men earning between 20,000 and 30,000 MKD per month participated with $14.2 \%$, and those with incomes from 12,000 to 20,000 MKD, participated with $11.8 \%$. 


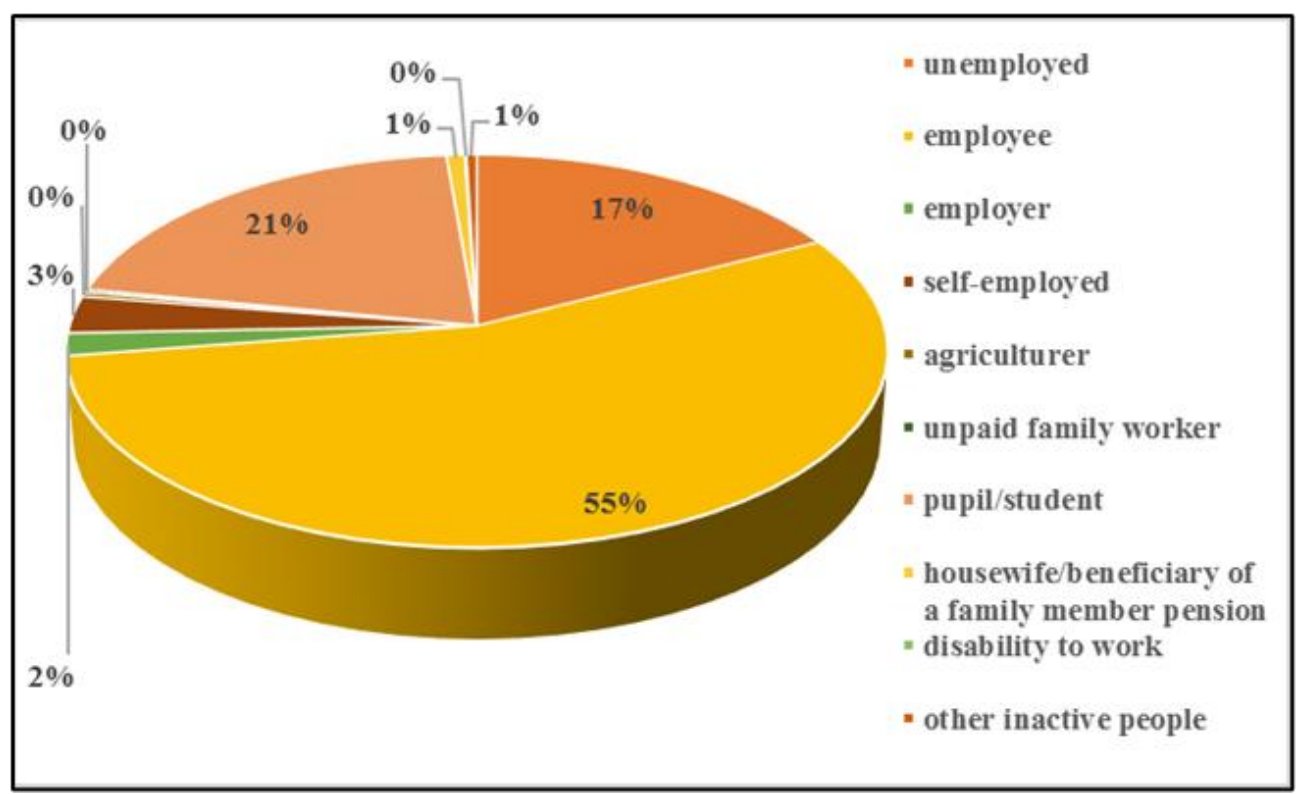

Figure 10. Respondents' status of economic activity at the time of the survey.

However, this analysis should be taken with a dose of reserve because a large part of the respondents, especially men are still involved in the educational process and are not job seekers, but also because the sample size of male and female respondents differs significantly.

The survey covers respondents from all parts of the country, but as most of the population in the country is located in the Skopje region, the share of respondents that origin from Skopje was $58.6 \%$.

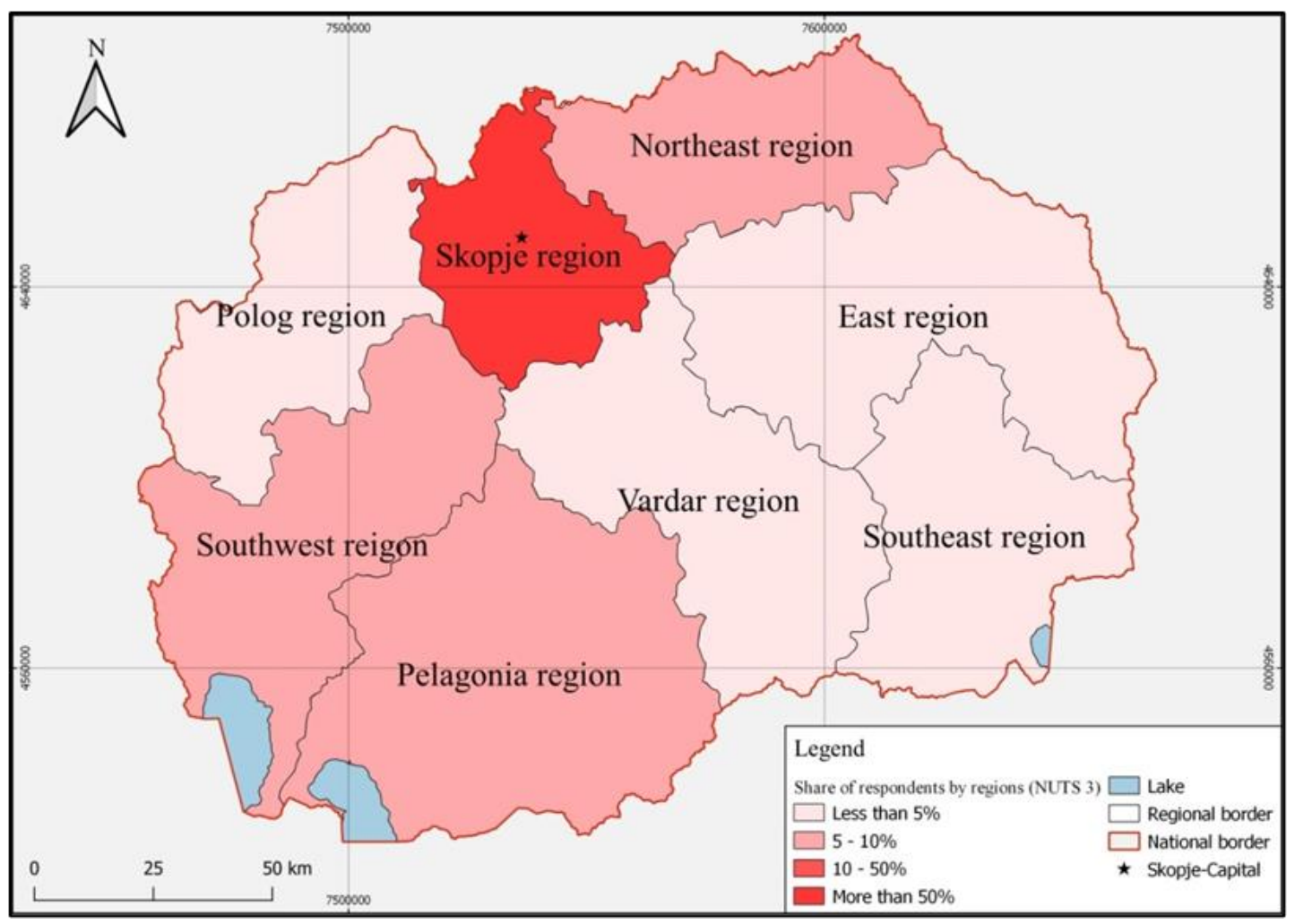

Figure 11. Share of respondents by region (NUTS 3 level) 


\section{CONCLUSION}

Vital statistics and census data clearly indicate to the changes that occurred over the years (number of marriages: 1991-15,311; 2002-14,522; 2019-13,814, number of live births: $\left.1991-34,830 ; 2002-27,761 ; 2019-19,845^{4}\right)$, but the data from the conducted empirical research pointed to the opinions and attitudes of respondents, highlighted the factors that influenced the decisions they make and the effects of the measures taken by the state authorities to improve the situation. The survey confirmed that: the education of the respondents affects the age of marriage and influences the attitude towards the ideal age for marriage; Education affects the desired number of children, but also the decision to give birth/have a child outside the marital union. The age of the respondents influences the attitude towards the years at which the persons should get married, the attitude about living with the partner before the marriage, but also about the decision to have a child outside the marital union. The age at which married respondents had a child in $80.75 \%$ was affected by the years at which they got married. The ethnicity of the respondents affects the number of children, but the impact of the finances has a great influence on this issue also.

Among the main reasons that influenced the decrease in the number of marriages are primarily the new perceptions and views of life, the new socio-economic conditions, the higher level of education, involvement in the labor market, especially for women, greater independence of individuals, the way of choosing a partner, age at marriage, and all of this accompanied by other demographic components, i.e., reduced birth rate, population gender and age inequality, migration, reduced number of generations of the marital contingent, etc. Hence, significant results can be obtained in analyzing the demographic characteristics of people who are about to marry [8].

The results from this research are only a starting point for further researches on this topic, which will ultimately help to create social policies, as well as to create population and family policies in harmony with the development trend of the population and its marital status. These policies are expected to include measures and activities that will further improve the situation with the demo-reproductive processes in the country [9].

The analysis of the modern demographic conditions is of particular importance for population policymakers, social scientists, demographers, and demo-geographers, as well as for anyone seeking to understand society, family, and marital behavior in order to anticipate future trends.

Seminars and conferences should also be organized to present the findings of specialized studies and scientific and professional researches in the field of fertility, marriage, and divorce, which will be attended by competent representatives of relevant government agencies, consulting providers, universities and research centers, various civil society institutions, and individuals interested in marriage and family matters.

\section{Acknowledgment}

The survey was part of the research for the doctoral thesis "Demogeographic development of marriage and fertility in the Republic of Macedonia", by Marija Ljakoska, defended on July 08, 2019, at the Ss. Cyril and Methodius University in Skopje, Faculty of Natural Sciences and Mathematics, Institute of Geography. 


\section{REFERENCES}

[1] Apostolovska Toshevska B., Madjevikj M., Ljakoska M. \& Sokoloski P. The reproductive behaᄀvior of the female population in the only Roma governed community in Europe, Human Geographies - Journal of Studies and Research in Human Geography, Romania, Vol. 12, No. 2, pp. 157-174, 2018;

[2] Bobić M. Recomposing of marriage, partnership and family in contemporary so $\neg$ cie $\neg$ ti-es, Population, Serbia, 1 (4, 2003), pp.65-91, 2003;

[3] Devedžić M. The impact of marriage on the fertility level, Demography, Serbia, I, pp.73-91, 2004;

[4] Golubović P. \& Marković Krstić S. Models of marital and reproductive behavior of population (using examples of Serbia, Macedonia and Bulgaria), Proceedings of the Conference, Social changes cultural and ethnic relations and euro integration processes at the Balkans, Serbia, 2004, pp.269-283;

[5] Hărăguş M. Childbearing outside Marriage in Romania. Romania: Center for Population Stu $\neg$ di $\neg$ es. Babeş-Bolyai University Cluj-Napoca;

[6] Ivković M., Todorić J. \& Mucić M. Marital behavior of the elderly population in Serbia, Matica Srpska, Department of social sciences quarterly, Serbia, 148 (3-2014), pp.677-685, 2014;

[7] Ljakoska M. \& Madjevikj M. Age differences of marrying couples - the case of North Mace $\neg$ do $\neg$ nia, Proceedings of the symposium dedicated to the 70th anniversary of the Macedonian Geo $\neg$ gra $\neg$ phical Society - New trends in geography, 3-4.10.2019, Ohrid, North Macedonia, pp. 247-257, 2019;

[8] Madzevikj M. Heterogeneous marriages in the Republic of Macedonia regarding ethnicity, Geographical Reviews, Republic of Macedonia, vol. 43, pp163-174, 2009;

[9] Madzevikj M. The population structure in the Republic of Macedonia according to the marital status, Proceedings of the Third Congress of Geographers of the Republic of Macedonia, Skopje, 15.10.2005, pp. 237-243, 2005;

[10] McLeod SA 2014. Attitudes and behavior.

Retrieved from www.simplypsychology.org/attitudes.html;

[11] Perelli-Harris B. Gerber T.P. Non-marital childbearing in Russia second demographic transition or pattern of disadvantage? Demography, 47 (4). 2010;

[12] Petrović R. Characteristics of marriage in Yugoslavia, Household, family and marriage in Yugoslavia. Belgrade, Serbia: ISI FF, 1981;

[13] Risteski S. \& Trpkova-Nestorovska M. Demography - methods and analysis. Skopje: Faculty of Economics, Republic of Macedonia, 2014;

[14] Serafimovska E. \& Markovikj M. Moral motivation as a predictor for activity in students' organization, Annual 2018, XLII / Special Issue, Institute for sociological, political and juridical research - Skopje, Macedonia, pp. 55-66, 2018;

[15] Vasić P. Non-marital fertility in central Serbia and Vojvodina since the beginning of 1990s. Demography, Serbia, IV, pp.37-54, 2007;

[16] Yanker D., Le Anderson D. \& Hickes Lundquist J. Demography, the study of human population. Illinois, USA: Waveland Press, Inc., 2007. 